\title{
Mecanismos adaptativos do sistema imunológico em resposta ao treinamento físico
}

\author{
Carol Góis Leandro1, Raul Manhães de Castro², Elizabeth Nascimento², Tânia Cristina Pithon-Curi³ e Rui Curi
}

\section{RESUMO}

O treinamento físico, de intensidade moderada, melhora os sistemas de defesa, enquanto que o treinamento intenso causa imunossupressão. Os mecanismos subjacentes estão associados à comunicação entre os sistemas nervoso, endócrino e imunológico, sugerindo vias autonômicas e modulação da resposta imune. Células do sistema imune, quando expostas a pequenas cargas de estresse, desenvolvem mecanismo de tolerância. Em muitos tecidos tem-se demonstrado que a resposta a situações agressivas parece ser atenuada pelo treinamento físico aplicado previamente, isto é, o treinamento induz tolerância para situações agressivas/estressantes. Nesta revisão são relatados estudos sugerindo os mecanismos adaptativos do sistema imunológico em resposta ao treinamento físico.

\section{ABSTRACT \\ Adaptative mechanisms of the immune system in response to physical training}

Moderate physical training enhances the defense mechanisms, while intense physical training induces to immune suppression. The underlying mechanisms are associated with the link between nervous, endocrine, and immune systems. It suggests autonomic patterns and modulation of immune response. Immune cells, when exposed to regular bouts of stress, develop a mechanism of tolerance. In many tissues, it has been demonstrated that the response to aggressive conditions is attenuated by moderate physical training. Thus, training can induce tolerance to aggressive/stressful situations. In this review, studies suggesting the adaptation mechanisms of the immune system in response to physical training will be reported.

\section{INTRODUÇÃO}

A relação entre exercício físico e saúde vem-se consolidando nos últimos anos. Em estudos clínicos, de ampla abordagem epidemiológica, foi demonstrado que a prática regular de exercício físico está associada à promoção da saúde e à prevenção de doenças crônico-degenerativas ${ }^{(1-2)}$. Recentemente, os efeitos do exercício físico sobre a função do sistema imunológico têm sido abordados em vários estudos ${ }^{(3-8)}$.

Diferentes tipos de exercício físico provocam alterações distintas na função imune. O exercício regular, ou treinamento físico,

1. Departamento de Nutrição, CAV - Universidade Federal de PernambuCO - UFPE.

2. Departamento de Nutrição, Universidade Federal de Pernambuco UFPE.

3. Instituto de Ciências Biomédicas ICB-1, Universidade de São Paulo USP.

Aceito em 14/6/07.

Endereço para correspondência: Carol Góis Leandro, Av. Prof. Moraes Rego, 1.235, Cidade Universitária - 50670-901 - Recife, PE, Brasil. Tel.: (81) 2126-8463, fax: (81) 2126-8470. E-mail: carolleandro22@yahoo.com.br
Palavras-chave: Exercício físico. Tolerância-cruzada. Leucócitos.

Keywords: Physical exercise. Cross-tolerance. Leukocytes.

de intensidade moderada melhora os sistemas de defesa, enquanto que o treinamento intenso causa imunossupressão(9-10). Os mecanismos subjacentes estão associados à comunicação entre os sistemas nervoso, endócrino e imunológico, sugerindo vias autonômicas e modulação da resposta imune ${ }^{(11)}$. Células do sistema imune, quando expostas a pequenas cargas de estresse, desenvolvem mecanismo de tolerância. Em muitos tecidos tem-se demonstrado que a resposta a situações agressivas parece ser atenuada pelo treinamento físico aplicado previamente, isto é, o treinamento induz tolerância para situações agressivas/estressantes ${ }^{(12-13)}$

Esta revisão tem por objetivo abordar alguns aspectos relevantes da influência do treinamento físico sobre a função de componentes do sistema imunológico. Para uma compreensão mais abrangente, serão relatados também estudos evidenciando os mecanismos prováveis de adaptação orgânica associados ao treinamento físico.

\section{O SISTEMA IMUNOLÓGICO: CONSIDERAÇÕES GERAIS}

O sistema imunológico é determinante no combate a microorganismos invasores, na remoção de células mortas e detritos celulares e no estabelecimento da memória imunológica ${ }^{(14)}$. As células que constituem o sistema imunológico originam-se a partir de células hematopoéticas pluripotentes, localizadas na medula óssea, e as diferenciações posteriores ocorrem não só aí como também noutros locais específicos do organismo. As populações leucocitárias compreendem os granulócitos polimorfonucleares (neutrófilos, eosinófilos e basófilos), os monócitos/macrófagos e os linfócitos (linfócitos T, B e células natural killer [NK]).

Os neutrófilos são importantes fagócitos do sangue e participam na reação inflamatória, sendo sensíveis a agentes quimiotáxicos liberados pelos mastócitos e basófilos assim como pela ativação do sistema complemento(15). A leucocitose por neutrofilia pode indicar a presença de uma infecção bacteriana ou de uma inflamação em resposta a uma lesão tecidual(14).

Uma outra linhagem de células fagocíticas inclui os mononucleados monócitos e macrófagos. Os monócitos são células presentes no sangue periférico que continuamente se diferenciam em macrófagos após migrarem para os tecidos ${ }^{(14)}$. Os macrófagos estão envolvidos na atividade microbicida e antitumoral e manifestam função celular acessória como apresentadores de antígeno(16). Aspectos característicos dos macrófagos incluem a capacidade de aderência, quimiotaxia, produção de espécies reativas de oxigênio e citotoxicidade ${ }^{(14,17)}$. São também uma fonte de citocinas mediadoras das reações fisiopatológicas que habitualmente acompanham a lesão celular(16).

Os macrófagos são células de alto poder fagocitário e suas funções são reguladas por outras células (linfócitos $T$ e $B)^{(18)}$ e por mediadores químicos produzidos pelo sistema nervoso simpático (SNS) e pelo eixo hipotálamo-pituitária-adrenal (HPA)(11,18). A pre- 
sença de glicocorticóides em culturas de macrófagos resulta na inibição de algumas funções microbicidas, por exemplo, a produção de espécies reativas de oxigênio (ERO) e nitrogênio (ERN) ${ }^{(17)}$. Os macrófagos também possuem efeitos pró e antiinflamatórios e promovem o desenvolvimento da imunidade mediada por linfócitos $^{(14)}$.

Os linfócitos são heterogêneos em tamanho e morfologia. As diferenças entre estas células são observadas quanto à razão núcleo/citoplasma e à presença ou não de grânulos citoplasmáti$\cos ^{(18)}$. Células de morfologia similar são encontradas no baço, medula óssea, linfonodos, timo, e outras áreas como as placas de Peyer ${ }^{(18)}$. Os linfócitos podem ser classificados de acordo com seus marcadores de membrana, reações a estímulos, padrões de migração e vida-média(14). No timo, ao adquirirem determinadas características, transformam-se em linfócitos $\mathrm{T}$, com marcadores antigênicos de superfície CD4+ (auxiliar - helper) ou CD8+ (supressor e citotóxico) ${ }^{(14,18)}$. Estas células fazem parte da resposta imunológica celular e proliferam ativamente quando estimuladas por interleucina-2 (IL-2) ou concanavalina A (ConA) ${ }^{(14,18)}$.

Apesar de não sintetizarem imunoglobulinas (lg), os linfócitos T atuam como moduladores da resposta imunológica(19). Isto se dá através de interações entre os vários tipos de linfócitos T com os macrófagos e as células dendríticas durante a resposta imunológica mediada por células ${ }^{(19)}$. Os linfócitos $B$ atingem a maturidade provavelmente na medula óssea e são precursores das células produtoras de anticorpos, os plasmócitos ${ }^{(19)}$. Quando estimulados por lipopolissacarídeos em cultura, estas células passam a se proliferar ${ }^{(20-21)}$.

Os linfócitos normalmente presentes na circulação e nos tecidos linfóides encontram-se em estado quiescente, situação na qual se apresentam metabolicamente pouco ativos ${ }^{(19)}$. Um estímulo do tipo invasivo ou neoplásico é capaz de promover a ativação dessas células, levando-as a proliferar e a secretar citocinas envolvidas na resposta imune ${ }^{(19)}$. A mudança para o estado ativado é também acompanhada por alterações metabólicas nestas células, em que as vias biossintéticas e energéticas são estimuladas ${ }^{(22-24)}$.

Há ainda as células NK, um tipo de linfócito encontrado no sangue. Estas células são conhecidas por desencadearem a defesa precoce contra certas infecções intracelulares e eliminação de células tumorais ${ }^{(19)}$.

A resposta local a uma infecção ou tecido lesionado envolve a produção de citocinas ${ }^{(19)}$. As citocinas são pequenas proteínas solúveis secretadas por leucócitos, e outras células, e que têm por função modular a resposta imune ${ }^{(25-26)}$. A resposta local para uma infecção ou tecido lesionado envolve a produção desses mediadores que vão facilitar o influxo dos vários tipos de leucócitos para a região atingida ${ }^{(25)}$. Além da sua ação mediadora no sistema imune, as citocinas podem também atuar em outros sistemas modificando, nestes, as suas funções ${ }^{(25,27)}$.

O sistema imune parece ser sensível tanto aos agentes infecciosos como às alterações na homeostase orgânica, como ocorre no estresse ${ }^{(11,28)}$. Essas alterações sugerem uma inter-relação do sistema imune com outros sistemas, como o nervoso e o endócrino ${ }^{(29)}$. A resposta hormonal é aparentemente padronizada e independentemente do tipo de agente estressor. Há inicialmente a ativação do SNS resultando em aumento na concentração de catecolaminas na circulação e, também, a ativação do eixo HPA que induz aumento na concentração de glicocorticóides e outros hormônios ${ }^{(30)}$. As células do sistema imunológico possuem receptores para tais hormônios ${ }^{(28,31-33)}$. Da mesma forma, podem secretar citocinas que vão atuar em órgãos neuroendócrinos ${ }^{(32)}$. Aliás, a relação bidirecional entre estes sistemas parece ser o marco do entendimento atual da atividade imunológica, demonstrando a forma multiconectada com que o sistema imune atua ${ }^{(31-33)}$. Neste sentido, muitos estudos têm-se voltado para a resposta do sistema imunológico a diferentes agentes indutores de estresse, como, por exemplo, o exercício físico.

\section{EXERCíCIO FÍSICO, TREINAMENTO FÍSICO E O SISTEMA IMUNOLÓGICO}

O exercício físico pode ser classificado de acordo com a intensidade do esforço como: leve, moderado e intenso. Essa classificação toma como base a realização de alguns testes de esforço máximo para avaliar a concentração de lactato no sangue, o consumo máximo de oxigênio $\left(\dot{V} \mathrm{O}_{2 \mathrm{max}}\right)$, e/ou a freqüência cardíaca máxima ( $\mathrm{FC}_{\max }$ ). Em exercícios de intensidade leve e moderada, a concentração de lactato no sangue permanece estável (variando entre 2 e $4 \mathrm{mmol} / \mathrm{L}$ ), ou seja, o lactato é produzido em taxas mais baixas $^{(34)}$. O $\dot{V} \mathrm{O}_{2 \max }$ e a $\mathrm{FC}_{\max }$ são os parâmetros fisiológicos mais comumente utilizados em estudos para referenciar a intensidade do esforço. Assim, um exercício leve geralmente refere de 20 a $50 \%$ do $\mathrm{V}_{2 \max }$ e da $\mathrm{FC}_{\max }$ um exercício moderado de $50-70 \%$ do $\dot{\mathrm{V}} \mathrm{O}_{2 \max }$ e da $\mathrm{FC}_{\max }$ e o exercício intenso acima de $80 \%$ do $\dot{\mathrm{V}} \mathrm{O}_{2 \max } \mathrm{e}$ da $\mathrm{FC}_{\max }(13,35-36)$. Se o exercício físico é realizado regularmente é denominado de treinamento físico.

O efeito de um exercício físico agudo (carga súbita de esforço físico) sobre as células do sistema imunológico já está bem estabelecido(6,9,37-39). Diferentes tipos e cargas de esforço podem ter repercussões distintas no sistema imunológico. O exercício moderado parece melhorar os mecanismos de defesa do organismo, enquanto que o exercício intenso parece enfraquecê-los ${ }^{(9-10,37)}$. Em resposta a um exercício físico intenso ocorre neutrofilia, linfopenia e monocitose ${ }^{(7)}$. A redistribuição destas células no compartimento vascular em resposta ao exercício parece ser mediada pela adrenalina, e em menor grau pela noradrenalina ${ }^{(29,33,40-41)}$. A expressão de $\beta$-receptores nas diferentes células imunes pode fornecer a base molecular para ação das catecolaminas ${ }^{(11)}$. Contudo, a densidade de receptores adrenérgicos e a eficiência do sistema de transdução AMPc diferem nos vários tipos de células imunocompetentes $^{(42-43)}$. Os neutrófilos e as células NK parecem apresentar maior número de receptores, sendo seguidos, por ordem decrescente, pelos linfócitos TCD8+, pelos linfócitos B e, finalmente, pelos linfócitos TCD4+(22,42,44)

O exercício físico intenso pode induzir inibição de muitos aspectos da defesa do organismo, incluindo a atividade das células NK, a resposta proliferativa dos linfócitos e a produção de anticorpos pelos plasmócitos ${ }^{(3,7,18,45)}$. Estas alterações comprometem a defesa do organismo contra agentes infecciosos e oncogênicos, assim como nos processos alérgicos e na auto-imunidade ${ }^{(10,31)}$. Gillis et al. ${ }^{(46)}$ observaram inibição na produção do fator de crescimento de linfócitos $T$ induzida pelo aumento de glicocorticóides. Woods et al.(47) verificaram diminuição na produção de superóxido por macrófagos peritoneais de ratos em resposta a uma carga intensa de exercício físico. Estes estudos suportam o conceito de imunossupressão induzida pelo estresse, pois, conforme referido acima, os linfócitos e os macrófagos atuam, de forma determinante, contra a carcinogênese e a auto-imunidade.

Por outro lado, o exercício físico moderado parece estar associado ao aumento da função de leucócitos. Muitos pesquisadores verificaram que o exercício físico moderado auxilia a quimiotaxia, desgranulação, fagocitose e atividade oxidativa dos neutrófilos uma hora após exercício físico a $60 \% \dot{V}_{2 m a x x}{ }^{(6,48-50)}$. Woods et al.(47) verificaram aumento da aderência, a produção de ânion superóxido, a taxa de metabolismo do nitrogênio, a atividade citotóxica e a capacidade fagocítica de macrófagos. Pedersen e Tvede(51) estudaram a resposta das populações de linfócitos em ciclistas dinamarqueses durante uma hora de exercício físico e verificaram aumento na atividade citolítica de células NK e da linfocina ativadora de células NK (LAK). Recentes estudos relatam que não ocorre alteração na concentração salivar de $\lg A$ e de $\lg E$, no soro, durante um exercício moderado ${ }^{(42,52-54)}$. De fato, já é bem estabelecido que o exercício físico moderado está associado ao aumento da função imunológica e a diminuição da suscetibilidade às doenças ${ }^{(55)}$. Diante de tais evidências, é plausível estabelecer um elo entre o treina- 
mento físico de intensidade moderada e as alterações ocorridas no sistema imunológico.

Ao contrário da grande quantidade de estudos realizados com exercício físico agudo, os relatos sobre a relação entre o treinamento físico e o sistema imune são poucos. É difícil controlar variáveis intervenientes como a dieta dos atletas, o período de competição, as viagens e o estresse psicológico, que podem, de forma independente, influenciar a função do sistema imune. Peters et al. ${ }^{(52)}$ reportaram uma menor incidência de infecções do trato respiratório superior (ITRS) em corredores suplementados com $600 \mathrm{mg}$ de vitamina $\mathrm{C}$ três dias antes da corrida, comparativamente aos seus pares. Também Robinson et al. ${ }^{(56)}$ verificaram que a adição de ácido graxo ômega 3 na dieta, independente do treinamento físico moderado, pode fornecer efeitos benéficos na função imune (aumento da atividade das células NK). Nieman et al. ${ }^{(57)}$, num estudo com maratonistas, relataram que $12 \%$ dos participantes tiveram $20 \%$ a mais de ocorrências de ITRS uma semana após a prova quando esta era realizada nos meses de inverno. Neste mesmo estudo, foi observada maior incidência de IRTS nos participantes no período que antecedia a prova quando comparados aos seus pares não participantes ${ }^{(57)}$.

Existe uma percepção geral de que os atletas de alto nível têm maiores riscos de adquirir infecções, como a ITRS, durante períodos de treinamento intenso (> $75 \%$ do $\dot{\mathrm{V}} \mathrm{O}_{2 \max }$ ) e após competições exaustivas ${ }^{(6,53)}$. Bury et al.(54) verificaram diminuição na resposta proliferativa de linfócitos $T$ e na função fagocítica de neutrófilos em futebolistas no período de competição. Uma explicação mais simplificada para a imunossupressão, em resposta a uma carga intensa de exercício físico, é a de que existe um desgaste aumentado das funções do organismo com produção exagerada de EROs e incremento do estresse oxidativo nos tecidos $^{(9,12)}$. Lin et al. ${ }^{(5)}$ verificaram que o aumento na ocorrência de apoptose em timócitos está associado à elevação na produção de EROs em ratos submetidos a dois dias de exercício físico intenso, tendo estes efeitos sido atenuados pela administração prévia do antioxidante hidroxianisol butilato.

Por outro lado, o treinamento físico de intensidade moderada parece melhorar muitas funções imunes(58). Pedersen et al.(51) avaliaram ciclistas treinados por 4 anos consecutivos e detectaram diminuição na incidência de infecções com conseqüente aumento da função imunológica. Atletas não competitivos ou indivíduos que aderem a uma prática regular de exercício leve ou moderado, comparativamente à população sedentária, apresentam maior proteção contra infecções ${ }^{(8,59-61)}$. Pastva et al. ${ }^{(62)}$ demonstraram que um treinamento de intensidade moderada diminui a infiltração de leucócitos, a produção de citocinas, expressão de moléculas de adesão e a remodulação estrutural nos pulmões de camundongos asmáticos. A função de neutrófilos e o índice de proliferação de linfócitos B não se alteraram em estudos realizados com humanos treinados ${ }^{(63)}$. Também, Nieman et al. ${ }^{(57)}$ demonstraram os efeitos do exercício moderado no aumento da resistência a infecções, verificando que mulheres que realizaram 45 minutos de caminhada cinco vezes por semana, no período de 15 semanas, tiveram menor incidência de dias relatados com IRTS.

A atividade citotóxica de células NK também parece aumentar em atletas não-competitivos após um período de treinamento de 8 meses $^{(64)}$. Em corredores treinados, Baum et al. ${ }^{(65)}$ não encontraram alteração na contagem diferencial de leucócitos na circulação 22 horas após a última sessão de treinamento moderado.

Em animais, foi observado aumento na função de macrófagos após um programa de treinamento moderado. Woods et al.(66) verificaram aumento na função fagocítica de macrófagos peritoneais de ratos após 12 semanas de natação. Bacurau et al.(48) verificaram que macrófagos de animais treinados e com tumor de Walker-256 apresentam aumento na atividade fagocítica. Foi também verificada elevação no índice de proliferação de linfócitos e no tempo de vida dos animais treinados com tumor quando comparados aos seus pares sedentários com tumor(48). Nosso grupo observou aumento na função fagocítica de macrófagos alveolares de ratos submetidos a 6 semanas de natação (5 dias/semana, 60 minutos/dia) ${ }^{(67)}$. Tais estudos evidenciam que as células do sistema imune parecem apresentar mecanismos adaptativos que permitem a melhoria da sua função em resposta ao exercício físico regular e de intensidade moderada ${ }^{(64,68)}$. Assim, a hipótese de que os efeitos benéficos do treinamento físico moderado podem atenuar o efeito de agentes estressores indutores de imunossupressão parece provável.

\section{TREINAMENTO FÍSICO MODERADO PRÉVIO A UM EXERCÍCIO FÍSICO INTENSO}

O efeito do treinamento moderado na resposta do sistema imune a um exercício agudo vem sendo estudado(4-5,53,64,69-70). Os animais são submetidos ao treinamento moderado e a seguir a cargas súbitas de exercício físico intenso, associando modelos de estresse crônico com o agudo. Lin et al. ${ }^{(5)}$ verificaram que a diminuição na percentagem das subpopulações de linfócitos $T$, da reposta mitogênica de linfócitos $B$ do baço e das concentrações sanguíneas de IL-2 após uma carga aguda de exercício físico intenso foi atenuada em animais previamente submetidos a 10 semanas de corrida moderada $\left(70 \%\right.$ do $\dot{\mathrm{V}} \mathrm{O}_{2 \mathrm{max}}$ ). Fu et al. ${ }^{(60)}$ verificaram que o treinamento moderado (durante 4 semanas) previne a diminuição de linfócitos TCD4+ no plasma avaliados 24 horas após uma carga de exercício físico agudo extenuante. Os resultados são indicativos de que a imunossupressão causada pelo exercício físico intenso parece diminuir em animais treinados com intensidade moderada. Os mecanismos subjacentes a estas respostas ainda permanecem desconhecidos, mas podem estar associados a fatores neuroendócrinos induzindo aumento da tolerância de leucócitos a um agente estressor(71).

Os sistemas neuroendócrino e imunológico são particularmente sensíveis a uma carga aguda de exercício físico, sendo verificado aumento de neurotransmissores, hormônios e citocinas no plas$\mathrm{ma}^{(32)}$. É interessante observar que, em resposta ao treinamento moderado, o aumento plasmático dos hormônios liberados em resposta a uma carga aguda de exercício físico parece ser atenuado(72). Nosso grupo verificou que, em ratos treinados (8 semanas a 70\% do $\dot{\mathrm{V}} \mathrm{O}_{2 \text { max }}$ ), as concentrações plasmáticas de corticosterona não alteraram 24 horas após a última sessão de exercício físico ${ }^{(13)}$. Kizaki et al. ${ }^{(73)}$ não verificaram aumento nos valores plasmáticos de corticosterona de animais treinados (natação durante 6 semanas, 5 dias/ semana, $90 \mathrm{~min} / \mathrm{dia}$ ) e posteriormente expostos ao estresse térmico $\left(5^{\circ} \mathrm{C}\right.$ durante 3 horas) quando comparados aos seus pares somente estressados. Chennaoui et al. ${ }^{(74)}$ verificaram, em ratos submetidos a treinamento moderado durante 6 semanas, que as concentrações plasmáticas de ACTH e corticosterona não foram afetados 24 horas após a última sessão de exercício. Também, Duclos et al. ${ }^{(72)}$ verificaram que, imediatamente após um exercício agudo e 24 horas depois, as concentrações de cortisol não aumentaram em homens treinados quando comparados aos seus pares sedentários. Estas e outras evidências apontam para o fato da ativação repetida do eixo HPA, tal como ocorre no exercício efetuado de forma regular, poder levar a uma adaptação na sua resposta a situações de agressão orgânica aguda. Mais especificamente, parece ocorrer menor sensibilidade adrenal ao ACTH(75-77). Tal hipótese vem sendo reforçada pelos resultados de Inder et al. ${ }^{(78)}$ e Duclos et al. ${ }^{(79)}$, nos quais o aumento das concentrações basais de ACTH no plasma não foi acompanhado de elevação de cortisol em homens treinados, comparativamente aos seus pares sedentários.

Algumas horas após a aplicação de uma carga aguda de exercício físico é de se esperar um direcionamento do perfil hormonal vocacionado para a estimulação dos processos anabólicos teciduais ${ }^{(77)}$. Dada a ação antagonista dos glicocorticóides neste processo nos músculos esqueléticos, a hipótese de que o treinamento físico pode desenvolver mecanismos de tolerância, tais como a 
sensibilidade diminuída ao cortisol, de forma a proteger os músculos da ação deste hormônio, parece razoável já que a elevação da concentração plasmática está associada ao catabolismo tecidual e, por conseguinte, à falência do processo de reparo de lesões pós-exercício ${ }^{(72,78-79)}$.

Em humanos, o treinamento físico pode estar associado a importantes alterações na imunorregulação induzida pelos glicocorticóides ${ }^{(74)}$. Em particular, parece haver sensibilidade reduzida dos linfócitos do sangue periférico para o efeito desses hormônios in vitro $^{(74)}$. Hoffman-Goetz et al.(61) observaram menor taxa de apoptose em timócitos de homens treinados quando expostos a glicocorticóides in vitro.

Sabe-se que uma carga aguda de exercício físico, mesmo que moderado, pode induzir apoptose em linfócitos ${ }^{(80)}$. A apoptose tem papel importante na embriogênese, morfogênese e regulação do número de células teciduais, mas a indução inapropriada de morte celular pode resultar numa variedade de efeitos patológicos tais como doença de Alzheimer, câncer e doenças auto-imunes crônicas (AIDS e lúpus eritematoso sistêmico) ${ }^{(37)}$. Os mecanismos subjacentes parecem estar relacionados com as alterações hormonais (aumento da concentração plasmática de glicocorticóides e catecolaminas), do cálcio citossólico e o estado redox celular(81-83).

O treinamento físico moderado, por sua vez, resulta em melhora nos mecanismos de defesa antioxidante e parece proteger as células imunes de lesões que podem levar à sua morte ${ }^{(70)}$. Observamos diminuição no percentual de linfócitos em apoptose induzida pela exposição a um modelo de estresse psicológico (contenção durante 60 minutos) em animais treinados ${ }^{(13)}$. Avula et al.(84) encontraram redução na apoptose de linfócitos induzida por $\mathrm{H}_{2} \mathrm{O}_{2}$, sem alteração na apoptose espontânea de linfócitos de camundongos exercitados durante 10 meses. É importante realçar a possível contribuição das proteínas de choque térmico (heat shock protein, HSP) principalmente no reparo das proteínas danificadas em resposta ao exercício intenso ${ }^{(85)}$. A indução da HSP70 parece proteger as células tímicas da apoptose induzida pelo estresse através da redução da expressão das proteínas p53 e Bax ${ }^{(85)}$. A indução da HSP70 pode, assim, representar um mecanismo importante através do qual os efeitos imunossupressores associados ao exercício agudo intenso podem ser minimizados ${ }^{(85)}$. Como seria de esperar, o treinamento físico moderado (70\% do $\dot{\mathrm{V}} \mathrm{O}_{2 \max }$ ) ou intenso (> $80 \% \dot{V}_{2 \max }$ ) aumenta a expressão das proteínas HSP70 e HSP90 em leucócitos ${ }^{(86)}$. Além das HSP, é sugerido que a proteína $\mathrm{Bcl}-2$ tenha alguma importância neste efeito protetor ${ }^{(87)}$. Siu et al. ${ }^{\left({ }^{85}\right)}$ verificaram que o treinamento físico (5 dias por semana, durante 8 semanas) atenua a extensão da apoptose no músculo cardíaco e esquelético de ratos. Esses autores associaram este resultado ao aumento do conteúdo de Bcl-2, HSP70 e MnSOD no miocárdio e músculo solear dos animais treinados quando comparados aos animais controle.

A morte da célula pode ser induzida via receptores de superfície celular Fas e ligante Fas (FasL) ou por citocinas pró-inflamatórias (TNF- $\alpha$ e IL-6) ${ }^{(88)}$. Ferenbarch e Northoff(86) documentaram aumento da expressão do FasL, após um agente estressor físico agudo, indicando ocorrência aumentada de apoptose em leucócitos. Por outro lado, em resposta ao treinamento, há diminuição dos indutores solúveis de apoptose: o FasL, o receptor Fas e o sFasL, uma citocina que induz apoptose quando se liga ao receptor Fas de membrana ativando as caspases $^{(88)}$. Adamopoulos et al. ${ }^{\left({ }^{89)}\right.}$ verificaram diminuição na expressão de Fas e FasL após exercício leve (> $50 \%$ do $\dot{\mathrm{V}} \mathrm{O}_{2 \max }$ ) e moderado $\left(60-70 \%\right.$ do $\left.\dot{\mathrm{V}} \mathrm{O}_{2 \max }\right)$. Os autores concluíram que o treinamento físico reduz o sistema Fas/ FasL e, por essa razão, tende a atenuar a apoptose. O treinamento físico parece também causar diminuição significativa na produção de citocinas pró-inflamatórias e seus receptores solúveis (TNFRI, TNF-RII e IL-6R), que são produtos da interação de células endoteliais com monócitos e, simultaneamente, moduladores biológicos da ação de citocinas circulantes ${ }^{(89)}$.
Além da via mediada pelo Fas, a morte celular pode também ser induzida via estresse oxidativo mitocondrial(70). Alterações no potencial transmembrânico mitocondrial (PTM) são seguidas de extravasamento de proteínas do espaço intermembranar, como o citocromo c e o fator de ativação de apoptose 1 (Apaf-1)(90). Estas moléculas desencadeiam a apoptose pela ativação das caspases ou pela condensação direta da cromatina independente de caspa$\operatorname{ses}^{(90)}$. Os sinais iniciais envolvem aumento na concentração de cálcio intracelular e/ou a formação de ERO e ERN (91). Para prevenir as lesões resultantes deste estresse oxidativo ou nitrosilativo, a célula está equipada com diferentes mecanismos de defesa. Substâncias antioxidantes como glutationa, ou enzimas como a superóxido-dismutase, glutationa-peroxidase e glutationa-redutase, parecem ter papel importante nessa proteção(92). Há várias evidências de que o treinamento regular está associado ao aumento dos mecanismos de proteção celular contra as EROs e ERNs ${ }^{(92-93)}$.

Quando há lesão do DNA, se não houver reparo, ocorre apoptose como mecanismo de defesa celular ${ }^{(91)}$. Tsai et al.(94) demonstraram que um agente estressor, a depender de sua magnitude, é habitualmente seguido pelo aumento da fragmentação de DNA. Observamos que, em animais treinados e sujeitos a um estressor agudo, não há alteração no percentual de células com o DNA fragmentado(13). Da mesma forma, em homens treinados e submetidos a uma maratona, há também diminuição do percentual de linfócitos apoptóticos do sangue quando comparados a sujeitos destreinados e submetidos ao mesmo esforço intenso(95). A instabilidade genômica após o estresse é menos pronunciada em ratos treinados ${ }^{(90)}$.

A p53 parece atuar como fator de transcrição induzido pela condição de estresse e possui papel importante na ativação e integração de grande quantidade de respostas celulares adaptativas para uma amplitude de agentes estressores ambientais ${ }^{(96)}$. Dependendo do tipo e da severidade do estresse celular, a p53 pode estar associada ou não a indução da apoptose ${ }^{(83,96)}$. Por exemplo, especificamente a apoptose induzida por radiação parece ser dependente da p53(96). O conteúdo de p53 é dramaticamente aumentado após a exposição à radiação X, radiação iônica, hipóxia e outros estressores que podem levar a uma apoptose massiva nos leucócitos ${ }^{(86)}$. Entretanto, a apoptose, em resposta ao aumento da concentração de glicocorticóides, parece ser independente da p53 ${ }^{(97)}$. Em células da granulosa humana, os glucocorticóides parecem protegê-las da apoptose, provavelmente aumentando o conteúdo de Bcl-2 nestas células $^{(87)}$. É possível que ocorra uma resposta cruzada entre a ação do TNF- $\alpha$ e dos glicocorticóides na modulação da apoptose, via controle das concentrações de $\mathrm{Bcl}-2^{(98-99)}$

O conteúdo de $\mathrm{Bcl}-2$ em linfócitos pode alterar o efeito próapoptótico dos glicocorticóides para um efeito antiapoptótico quando estes são expostos a um agente estressor ${ }^{(100)}$. Os glicocorticóides podem também impedir a sinalização da p53 na indução da apoptose e, com isso, prevenir a lesão excessiva de células após diferentes tipos de agentes estressores implicados no aumento da expressão da p53(97). Em células tímicas, o treinamento parece atenuar o percentual de linfócitos apoptóticos ${ }^{(101)}$. É provável que as adaptações ocorridas decorram do aumento da IL-2, a qual, por sua vez, aumenta o conteúdo de mRNA da Bcl-2(85).

Em vista do exposto, as alterações homeostáticas em resposta a situações agressivas, como o exercício físico intenso, parecem ser atenuadas pela aplicação de um treinamento físico moderado prévio. As células do sistema imune parecem apresentar mecanismos adaptativos de tolerância que permitem melhora da sua função em resposta ao exercício físico regular e de intensidade moderada.

Todos os autores declararam não haver qualquer potencial conflito de interesses referente a este artigo. 


\section{REFERÊNCIAS}

1. Farrell SW, Kampert JB, Kohl HW, 3rd, Barlow CE, Macera CA, Paffenbarger RS, et al. Influences of cardiorespiratory fitness levels and other predictors on cardiovascular disease mortality in men. Med Sci Sports Exerc. 1998;30:899-905.

2. Bousquet-Santos K, Vaisman M, Barreto ND, Cruz-Filho RA, Salvador BA, Frontera WR, et al. Resistance training improves muscle function and body composition in patients with hyperthyroidism. Arch Phys Med Rehabil. 2006;87:1123-30.

3. Pedersen BK, Tvede N, Hansen FR, Andersen V, Bendix T, Bendixen G, et al. Modulation of natural killer cell activity in peripheral blood by physical exercise. Scand J Immunol. 1988;27:673-8.

4. Nehlsen-Cannarella SL, Nieman DC, Balk-Lamberton AJ, Markoff PA, Chritton DB, Gusewitch $G$, et al. The effects of moderate exercise training on immune response. Med Sci Sports Exerc. 1991;23:64-70.

5. Lin YS, Jan MS, Chen HI. The effect of chronic and acute exercise on immunity in rats. Int J Sports Med. 1993;14:86-92.

6. Nieman DC. Is infection risk linked to exercise workload? Med Sci Sports Exerc. 2000;32:S406-11.

7. Pedersen BK, Hoffman-Goetz L. Exercise and the immune system: regulation, integration, and adaptation. Physiol Rev. 2000;80:1055-81.

8. Davidson SR, Burnett M, Hoffman-Goetz L. Training effects in mice after longterm voluntary exercise. Med Sci Sports Exerc. 2006;38:250-5.

9. Angeli A, Minetto M, Dovio A, Paccotti P. The overtraining syndrome in athletes: a stress-related disorder. J Endocrinol Invest. 2004;27:603-12.

10. da Nobrega AC. The subacute effects of exercise: concept, characteristics, and clinical implications. Exerc Sport Sci Rev. 2005;33:84-7.

11. Besedovsky HO, del Rey AE, Sorkin E. Immune-neuroendocrine interactions. J Immunol. 1985;135:750s-4s.

12. Ascensao A, Magalhaes J, Soares J, Oliveira J, Duarte JA. Exercise and cardiac oxidative stress. Rev Port Cardiol. 2003;22:651-78.

13. Leandro CG, Martins de Lima T, Folador A, Alba-Loreiro T, do Nascimento E, Manhaes de Castro R, et al. Physical training attenuates the stress-induced changes in rat t-lymphocyte function. Neuroimmunomodulation. 2006;13:105-13.

14. Schulenburg H, Kurz CL, Ewbank JJ. Evolution of the innate immune system: the worm perspective. Immunol Rev. 2004;198:36-58.

15. Mabbott NA. The complement system in prion diseases. Curr Opin Immunol. 2004;16:587-93.

16. Boscolo P, Di Gioacchino M, Qiao N, Sabbioni E. Work, environment, immune system and human health. Int J Immunopathol Pharmacol. 2004;17:1-2.

17. Di Rosa M, Radomski M, Carnuccio R, Moncada S. Glucocorticoids inhibit the induction of nitric oxide synthase in macrophages. Biochem Biophys Res Commun. 1990;172:1246-52.

18. Peres CM, Otton R, Curi R. Modulation of lymphocyte proliferation by macrophages and macrophages loaded with arachidonic acid. Cell Biochem Funct. 2005; 23:373-81.

19. Hames B, Glover D. Molecular Immunology, in frontiers in molecular biology. 2nd ed. Oxford; 1996

20. Verlengia R, Gorjao R, Kanunfre CC, Bordin S, de Lima TM, Curi R. Effect of arachidonic acid on proliferation, cytokines production and pleiotropic genes expression in Jurkat cells - a comparison with oleic acid. Life Sci. 2003;73:2939-51.

21. Verlengia R, Gorjao R, Kanunfre CC, Bordin S, Martins De Lima T, Martins EF, et al. Comparative effects of eicosapentaenoic acid and docosahexaenoic acid on proliferation, cytokine production, and pleiotropic gene expression in Jurkat cells. J Nutr Biochem. 2004;15:657-65

22. Lagranha CJ, de Lima TM, Senna SM, Doi SQ, Curi R, Pithon-Curi TC. The effect of glutamine supplementation on the function of neutrophils from exercised rats. Cell Biochem Funct. 2005;23:101-7.

23. Nascimento E, Manhães-de-Castro R, Castro CM, Leandro CG. Pode a glutamina modular a imunidade? Anais Fac Med UFPE. 2001;46(2):67-70.

24. Pithon-Curi TC, De Melo MP, Curi R. Glucose and glutamine utilization by rat lymphocytes, monocytes and neutrophils in culture: a comparative study. Cell Biochem Funct. 2004;22:321-6

25. Vizi ES. Receptor-mediated local fine-tuning by noradrenergic innervation of neuroendocrine and immune systems. Ann N Y Acad Sci. 1998;851:388-96.

26. Gleeson M. Interleukins and exercise. J Physiol. 2000;529 Pt 1:1.

27. Besedovsky HO, del Rey A. Regulating inflammation by glucocorticoids. Nat Immunol. 2006;7:537

28. Besedovsky HO, del Rey A. Immune-neuro-endocrine interactions: facts and hypotheses. Endocr Rev. 1996;17:64-102

29. Blalock JE. The syntax of immune-neuroendocrine communication. Immunol Today. 1994;15:504-11.

30. Seltzer JG. Stress and the general adaptation syndrome or the theories and concepts of Hans Selye. J Fla Med Assoc. 1952;38:481-5.

31. Atanackovic D, Kroger H, Serke S, Deter HC. Immune parameters in patients with anxiety or depression during psychotherapy. J Affect Disord. 2004;81:201-9.
32. Faure M, Gapin L, Viret C. Stressing the virtues of the immune system. Microbes Infect. 2004;6:960-4

33. Garcia C, de Oliveira MC, Verlengia R, Curi R, Pithon-Curi TC. Effect of dexamethasone on neutrophil metabolism. Cell Biochem Funct. 2003;21:105-11.

34. Silveira L, Denadai B. Efeito modulatório de diferentes intensidades de esforço sobre a via glicolítica durante o exercício contínuo e intermitente. Rev Paulista Educ Fis. 2003;16(2):186-97

35. Hoffman-Goetz L. Influence of physical activity and exercise on innate immunity. Nutr Rev. 1998;56:S126-30

36. Pyne DB, Gleeson M, McDonald WA, Clancy RL, Perry C Jr, Fricker PA. Training strategies to maintain immunocompetence in athletes. Int J Sports Med. 2000; 21 (Suppl 1):S51-60.

37. Lagranha CJ, Senna SM, de Lima TM, Silva EP, Doi SQ, Curi R, et al. Beneficial effect of glutamine on exercise-induced apoptosis of rat neutrophils. Med Sci Sports Exerc. 2004;36:210-7.

38. Niess AM, Baumann M, Roecker K, Horstmann T, Mayer F, Dickhuth HH. Effects of intensive endurance exercise on DNA damage in leucocytes. J Sports Med Phys Fitness. 1998;38:111-5.

39. Leandro CG, Nascimento E, Manhães-de-Castro R, Duarte JA, de-Castro CM Exercício físico e sistema imunológico: mecanismos e integrações. Rev Port Cien Desp. 2002;2(5):80-90

40. Besedovsky HO, del Rey A. Introduction: immune-neuroendocrine network. Front Horm Res. 2002;29:1-14.

41. Besedovsky HO, del Rey A. Immune-neuroendocrine circuits: integrative role of cytokines. Front Neuroendocrinol. 1992;13:61-94.

42. Miller AH. Neuroendocrine and immune system interactions in stress and depression. Psychiatr Clin North Am. 1998;21:443-63

43. Kohut ML, Thompson JR, Lee W, Cunnick JE. Exercise training-induced adaptations of immune response are mediated by beta-adrenergic receptors in aged but not young mice. J Appl Physiol. 2004;96:1312-22.

44. Pithon-Curi TC, Trezena AG, Tavares-Lima W, Curi R. Evidence that glutamine is involved in neutrophil function. Cell Biochem Funct. 2002;20:81-6.

45. Jonsdottir IH. Exercise immunology: neuroendocrine regulation of NK-cells. Int J Sports Med. 2000;21(Suppl 1):S20-3.

46. Gillis S, Crabtree GR, Smith KA. Glucocorticoid-induced inhibition of T cell growth factor production. I. The effect on mitogen-induced lymphocyte proliferation. $J$ Immunol. 1979;123:1624-31.

47. Woods JA, Davis JM, Mayer EP, Ghaffar A, Pate RR. Effects of exercise on macrophage activation for antitumor cytotoxicity. J Appl Physiol. 1994;76:2177-85.

48. Bacurau RF, Belmonte MA, Seelaender MC, Costa Rosa LF. Effect of a moderate intensity exercise training protocol on the metabolism of macrophages and lymphocytes of tumour-bearing rats. Cell Biochem Funct. 2000;18:249-58.

49. Bruunsgaard H, Pedersen BK. Special feature for the Olympics: effects of exercise on the immune system: effects of exercise on the immune system in the elderly population. Immunol Cell Biol. 2000;78:523-31

50. Gleeson M, Pyne DB. Special feature for the Olympics: effects of exercise on the immune system: exercise effects on mucosal immunity. Immunol Cell Biol. 2000; 78:536-44

51. Pedersen BK, Tvede N. The immune system and physical training. Ugeskr Laeger. 1993;155:856-62

52. Peters EM, Goetzsche JM, Grobbelaar B, Noakes TD. Vitamin C supplementation reduces the incidence of postrace symptoms of upper-respiratory-tract infection in ultramarathon runners. Am J Clin Nutr. 1993;57:170-4.

53. Lancaster GI, Halson SL, Khan Q, Drysdale P, Wallace F, Jeukendrup AE, et al Effects of acute exhaustive exercise and chronic exercise training on type 1 and type 2 T lymphocytes. Exerc Immunol Rev. 2004;10:91-106

54. Bury T, Marechal R, Mahieu P, Pirnay F. Immunological status of competitive football players during the training season. Int J Sports Med. 1998;19:364-8.

55. Dos Santos Cunha WD, Giampietro MV, De Souza DF, Vaisberg M, Seelaender $\mathrm{MC}$, et al. Exercise restores immune cell function in energy-restricted rats. Med Sci Sports Exerc. 2004;36:2059-64.

56. Robinson LE, Field CJ. Dietary long-chain (n-3) fatty acids facilitate immune cell activation in sedentary, but not exercise-trained rats. J Nutr. 1998;128:498-504

57. Nieman DC, Buckley KS, Henson DA, Warren BJ, Suttles J, Ahle JC, et al. Immune function in marathon runners versus sedentary controls. Med Sci Sports Exerc. 1995;27:986-92.

58. Makras P, Koukoulis GN, Bourikas G, Papatheodorou G, Bedevis K, Menounos P, et al. Effect of 4 weeks of basic military training on peripheral blood leucocytes and urinary excretion of catecholamine and cortisol. J Sports Sci. 2005;23:82534.

59. Escribano BM, Aguera El, Vivo R, Santisteban R, Castejon FM, Rubio MD. Benefits of moderate training to the nonspecific immune response of colts. Equine Vet J Suppl. 2002:182-5 
60. Fu SC, Oin L, Leung CK, Chan BP, Chan KM. Regular moderate exercise training prevents decrease of CD4+ T-lymphocytes induced by a single bout of strenuous exercise in mice. Can J Appl Physiol. 2003;28:370-81.

61. Hoffman-Goetz L, Duerrstein L. The effect of chronic and acute exercise on thymocyte apoptosis and necrosis in ovariectomized mice given dietary genistein. $J$ Sports Med Phys Fitness. 2004;44:281-7.

62. Pastva A, Estell K, Schoeb TR, Atkinson TP, Schwiebert LM. Aerobic exercise attenuates airway inflammatory responses in a mouse model of atopic asthma. J Immunol. 2004;172:4520-6.

63. Nehlsen-Cannarella SL. Cellular responses to moderate and heavy exercise. Can J Physiol Pharmacol. 1998;76:485-9.

64. Mackinnon LT. Chronic exercise training effects on immune function. Med Sci Sports Exerc. 2000;32:S369-76.

65. Baum M, Liesen H, Enneper J. Leucocytes, lymphocytes, activation parameters and cell adhesion molecules in middle-distance runners under different training conditions. Int J Sports Med. 1994;15(Suppl 3):S122-6.

66. Woods J, Lu Q, Ceddia MA, Lowder T. Special feature for the Olympics: effects of exercise on the immune system: exercise-induced modulation of macrophage function. Immunol Cell Biol. 2000;78:545-53.

67. Nascimento E, Cavalcante T, Pereira S, Palmeira A, Rocha MC, Viana MT, et al. O exercício físico crónico altera o perfil leucocitário e a taxa de fagocitose de ratos estressados. Rev Port Cien Desp. 2004;4(3):26-33.

68. Friman G, Wesslen L. Special feature for the Olympics: effects of exercise on the immune system: infections and exercise in high-performance athletes. Immunol Cell Biol. 2000;78:510-22

69. Liu J, Yeo HC, Overvik-Douki E, Hagen T, Doniger SJ, Chyu DW, et al. Chronically and acutely exercised rats: biomarkers of oxidative stress and endogenous antioxidants. J Appl Physiol. 2000;89:21-8.

70. Mooren FC, Lechtermann A, Volker K. Exercise-induced apoptosis of lymphocytes depends on training status. Med Sci Sports Exerc. 2004;36:1476-83.

71. Forner MA, Barriga C, Rodriguez AB, Ortega E. A study of the role of corticosterone as a mediator in exercise-induced stimulation of murine macrophage phagocytosis. J Physiol. 1995;488(Pt 3):789-94.

72. Duclos M, Corcuff JB, Pehourcq F, Tabarin A. Decreased pituitary sensitivity to glucocorticoids in endurance-trained men. Eur J Endocrinol. 2001;144:363-8.

73. Kizaki T, Haga S, Sakata I, Ookawara T, Segawa M, Sakurai T, et al. Swimming training prevents generation of suppressor macrophages during acute cold stress. Med Sci Sports Exerc. 2000;32:143-8.

74. Chennaoui M, Gomez Merino D, Lesage J, Drogou C, Guezennec CY. Effects of moderate and intensive training on the hypothalamo-pituitary-adrenal axis in rats Acta Physiol Scand. 2002;175:113-21.

75. Gomez-Merino D, Drogou C, Chennaoui M, Tiollier E, Mathieu J, Guezennec CY. Effects of combined stress during intense training on cellular immunity, hormones and respiratory infections. Neuroimmunomodulation. 2005;12:164-72.

76. Jacobson L. Hypothalamic-pituitary-adrenocortical axis regulation. Endocrinol Metab Clin North Am. 2005;34:271-92, vii.

77. Luger A, Deuster PA, Kyle SB, Gallucci WT, Montgomery LC, Gold PW, et al Acute hypothalamic-pituitary-adrenal responses to the stress of treadmill exercise. Physiologic adaptations to physical training. N Engl J Med. 1987;316:1309 15.

78. Inder WJ, Hellemans J, Ellis MJ, Evans MJ, Livesey JH, Donald RA. Elevated basal adrenocorticotropin and evidence for increased central opioid tone in highly trained male athletes. J Clin Endocrinol Metab. 1995;80:244-8.

79. Duclos M, Gouarne C, Bonnemaison D. Acute and chronic effects of exercise on tissue sensitivity to glucocorticoids. J Appl Physiol. 2003;94:869-75

80. Hsu TG, Hsu KM, Kong CW, Lu FJ, Cheng H, Tsai K. Leukocyte mitochondria alterations after aerobic exercise in trained human subjects. Med Sci Sports Exerc. 2002;34:438-42
81. Curi TC, De Melo MP, Palanch AC, Miyasaka CK, Curi R. Percentage of phagocytosis, production of $\mathrm{O} 2 .-, \mathrm{H} 2 \mathrm{O} 2$ and $\mathrm{NO}$, and antioxidant enzyme activities of rat neutrophils in culture. Cell Biochem Funct. 1998;16(1):43-9.

82. Otton R, Soriano FG, Verlengia R, Curi R. Diabetes induces apoptosis in lymphocytes. J Endocrinol. 2004;182:145-56

83. Pithon-Curi TC, Schumacher RI, Freitas JJ, Lagranha C, Newsholme P, Palanch AC, et al. Glutamine delays spontaneous apoptosis in neutrophils. Am J Physiol Cell Physiol. 2003;284:C1355-61.

84. Avula CP, Muthukumar AR, Zaman K, McCarter R, Fernandes G. Inhibitory effects of voluntary wheel exercise on apoptosis in splenic lymphocyte subsets of C57BL/6 mice. J Appl Physiol. 2001;91:2546-52.

85. Siu PM, Bryner RW, Martyn JK, Alway SE. Apoptotic adaptations from exercise training in skeletal and cardiac muscles. Faseb J. 2004;18:1150-2.

86. Fehrenbach $\mathrm{E}$, Northoff $\mathrm{H}$. Free radicals, exercise, apoptosis, and heat shock proteins. Exerc Immunol Rev. 2001;7:66-89.

87. Sasson R, Tajima K, Amsterdam A. Glucocorticoids protect against apoptosis induced by serum deprivation, cyclic adenosine 3',5'-monophosphate and p53 activation in immortalized human granulosa cells: involvement of $\mathrm{Bcl}-2$. Endocrinology. 2001;142:802-11.

88. Sata M, Walsh K. TNFalpha regulation of Fas ligand expression on the vascular endothelium modulates leukocyte extravasation. Nat Med. 1998;4:415-20.

89. Adamopoulos S, Parissis J, Karatzas D, Kroupis C, Georgiadis M, Karavolias G, et al. Physical training modulates proinflammatory cytokines and the soluble Fas/soluble Fas ligand system in patients with chronic heart failure. J Am Coll Cardiol. 2002;39:653-63.

90. Ueda S, Masutani H, Nakamura H, Tanaka T, Ueno M, Yodoi J. Redox control of cell death. Antioxid Redox Signal. 2002;4:405-14.

91. Baumann S, Krueger A, Kirchhoff S, Krammer PH. Regulation of T cell apoptosis during the immune response. Curr Mol Med. 2002;2:257-72.

92. Silveira LR, Pilegaard $H$, Kusuhara K, Curi R, Hellsten $Y$. The contraction induced increase in gene expression of peroxisome proliferator-activated receptor (PPAR)gamma coactivator 1alpha (PGC-1alpha), mitochondrial uncoupling protein 3 (UCP3) and hexokinase II (HKII) in primary rat skeletal muscle cells is dependent on reactive oxygen species. Biochim Biophys Acta. 2006;1763:969-76.

93. Hirabara SM, Silveira LR, Alberici LC, Leandro CV, Lambertucci RH, Polimeno $\mathrm{GC}$, et al. Acute effect of fatty acids on metabolism and mitochondrial coupling in skeletal muscle. Biochim Biophys Acta. 2006;1757:57-66.

94. Tsai K, Hsu TG, Hsu KM, Cheng H, Liu TY, Hsu CF, et al. Oxidative DNA damage in human peripheral leukocytes induced by massive aerobic exercise. Free Radic Biol Med. 2001;31:1465-72.

95. Miyazaki H, Oh-ishi S, Ookawara T, Kizaki T, Toshinai K, Ha S, et al. Strenuous endurance training in humans reduces oxidative stress following exhausting exercise. Eur J Appl Physiol. 2001;84:1-6

96. Fridman JS, Lowe SW. Control of apoptosis by p53. Oncogene. 2003;22:9030 40.

97. Lee MC, Lee JS, Lee MJ, Lee JH, Kim HI. Fas mediates apoptosis in steroidinduced myopathy of rats. Neuropathol Appl Neurobiol. 2001;27:396-402.

98. Crochemore C, Michaelidis TM, Fischer D, Loeffler JP, Almeida OF. Enhancement of p53 activity and inhibition of neural cell proliferation by glucocorticoid receptor activation. Faseb J. 2002;16:761-70.

99. Huang ST, Cidlowski JA. Glucocorticoids inhibit serum depletion-induced apoptosis in T lymphocytes expressing Bcl-2. Faseb J. 1999;13:467-76.

100. Amsterdam A, Sasson R. The antiinflammatory action of glucocorticoids is mediated by cell type specific regulation of apoptosis. Mol Cell Endocrinol. 2002; 189:1-9.

101. Concordet JP, Ferry A. Physiological programmed cell death in thymocytes is induced by physical stress (exercise). Am J Physiol. 1993;265:C626-9. 